infiltration. No post mortem examination was had, in consequence of his :esidence being fifty miles distant from Aberdeen.

CASE CXCVIII. - James Clarke, aged 55, mason, came under treatmest on March 6th, 1865, and was operated on April Ist. The stme weighed 2 ounces $I \frac{1}{2}$ drachms, and measured $2 \frac{1}{2}$ inches by 2 irches by $I$ inch. With a quiet pulse, and urine both clear and cpious, he went on favourably for eight days, the tongue only being dry ; yet his desire for food was natural. On the ninth day, the pulse quickened a little; but there was no tenderness or local symptom anywhere, and he still took his food. On the twelfth day, he became faint, after sitting up in bed; and, continuing feeble, he expired on the evening of the thirteenth day (April 13th). Inspection revealed a collection of thick pus in the cellular tissue around the wound and neck of the bladder. The viscera of the abdomen were quite healthy. The coats of the bladder were thick and chronically inflamed.

CASE CCIII. - David Stewart, aged 79, farmer, was admitted on July 7 th, 1866, and was operated on July 14th, The stone weighed $7 \frac{1}{2}$ drachms, and measured $1 \frac{1}{2}$ inches by $1 \frac{1}{1}$ inches by $1 \frac{1}{8}$ inches. The patient was a large-built man, with a deep perinæum and a large cartilaginous prostate gland; yet the blunt gorget and chloroform made the operation easy. He went on well till the evening of the fifth day, when, after some freedom used in getting out of bed, he had a rigor, quickly followed by tenderness in the right pubic region, where a reducible hernia existed. The secretion of urine at the same time became nearly suspended. Leeches to the groin abated the pain and tenderness; but, although the general symptoms seemed at times cheering, the urine never came in natural quantity, and he gradually sank on the eighth day. Inspection revealed pus in the hernial sac, and a pinkish blush on the adjoining peritoneum. The liver was nutmeggy and friable; the kidneys were much diseased ; the bladder sacculated and greatly hypertrophied.

CASE CCV.-James Sim, aged 75, farm-servant, was admitted on February $13^{\text {th, }} 1867$, and was operated on February 28th. The stone weighed 5 ounces 7 drachms, and measured 3 inches by $1 \frac{3}{4}$ inches by $2 \frac{1}{2}$ inches. He went on most favourably till the sixth day, when, the bowels not having moved, a moderate dose of castor-oil was given. It operated twice comfortably; but, from the moment it did so, he felt weak, the urine began to flow less copiously, and he became drowsy. Sinapisms were applied to the nape of the neck, and turpentine stupes to the loins. Brandy and spirits of nitre were given freely; but the secretion of urine never returned in quantity; the pulse, never before above 60 , now quickened; his strength failed; and he quietly expired at 3 A.M. on March 7 th. Inspection revealed no very unusual appearances in the wound or its surroundings. The walls of the bladder were thickened and rugous, and congested on its inner surface. The fundus of the bladder outside the cellular tissue looked as if exudation of lymph had taken place, and was undergoing the process of softening and becoming purulent; but no adherent or reddened spot could be detected on the intestinal or pelvic peritoneum. The kidneys were small and diseased; the ureters were as large as a man's thumb ; and the pelves of both kidneys widely distended.

CASE CCXVI.-John Fraser, aged 67, crofter, was admitted on June 5 th, 1869 , and was operated on on June 16 th, when a calculus weighing $I$ ounce, and measuring $1 \frac{3}{4}$ inches by $I \frac{1}{2}$ inches by $\frac{3}{4}$ inch, was removed. He died on the eleventh day after the operation, without one untoward symptom connected with the kidneys or bladder. Pain at the pit of the stomach, and latterly coffee-ground vomiting, preceded his death. Post mortem examination revealed cancer of the pylorus and ulceration of the mucous membrane of the stomach. It turned out, on inquiry, that he had laboured many months under that disease, but had studiously concealed it.

CASE CCXIX proved fatal two days after the operation. No details are given in Dr. Keith's tables, further than the weight of the stone and the date of death.

\section{EMBOLISM OF THE CENTRAL ARTERY OF THE RETINA.}

By C. S. JEAFFRESON, Assistant-Surgeon, Newcastle-on-Tyne Infirmary.

AlthoUgh most ophthalmic surgeons must have seen cases of embolism of the central artery of the retina, they are still of sufficient rarity to be worth putting upon record.

R. M., aged 28 , whilst following his usual occupation as a bricklayer, became suddenly conscious of the rapid approach of blindness in his right eye. He described the blindness as having commenced in the centre of the field of vision, and gradually spread towards the periphery with such an amount of rapidity that, in a few moments, total darkneșs was produced. He left his work in great alarm, and the following day presented himself to me.

On examining the state of vision I found the left eye normal. In the right eye the whole field of vision was obscured, with the exception of a small portion in which it was highly amblyopic, recognising only obscurely the presence of the finger when held up. After his pupils had been thoroughly dilated with atropine, I examined him with the ophthalmoscope. The size, colour, and shape of the optic disc, the reflection from the fundus, and the condition of the vessels on the left side, were normal. On the right side, the optic disc was unaltered in colour, but the retinal arteries were reduced to the most minute threads, the veins congested, and for some distance surrounding the macula lutea there was a paleness of the fundus which made the redness of that spot stand out in prominent contrast. On searching for signs of cardiac disease, I found that, although there was no murmur of any kind, there was distinct evidence of hypertrophy, and that the heart's action was irregular and intermittent.

The chief peculiarities in this case are, the manner in which the blindness supervened, and the retention of a certain amount of vision in a very small portion of the field. The former I believe never before to have been noticed; and the latter, though noticed, not satisfactorily explained.

The only explanation I can offer of a portion of the field of vision still retaining sensibility is, that some spot in the retina must derive its blood-supply, partially, at least, from some other source than the retinal artery ; and if vision improve, we must expect to find it increasing the area of this spot, where if any collateral circulation is established, we may most reasonably look for it.

\section{WAS P..ST I N GS.}

\section{BY C. D. H. DRURY, Pulham St. Mary.}

DURING the last fortnight or three weeks, I have been called upon to treat no less than seven cases of illness arising from the stings of wasps.

On August 2 Ist, my cook, while making pastry, was stung in the forefinger of the right hand by a wasp. In less than half an hour she felt exceedingly depressed and weak, and complained of severe headache ; and her hand was so swollen that she could not bend her fingers. The eyes were red and bathed in tears; the face puffy, swollen, and dusky; and she was completely covered with an urticarious eruption. I could not find any remnant of the sting in the finger, and only with difficulty the place where the sting had entered. I ordered her at once to bed, and gave her fifteen minims of aromatic spirits of ammonia every half hour. She dipped her hand in a strong solution of carbonate of soda, but this only increased the pain; poultices, however, gave immediate relief. The ammonia, too, seemed to do much good; for after two doses the headache abated, the rash began to decline, and she felt much better, although the local pain remained. She scarcely closed her eyes all night, and in the morning I found the arm much swollen as far as the axilla-where she now complained of most pain, although I could not detect that the glands there were increased in size. The lymphatics of the forearm were enlarged and hard. Poultices were continued, the hand was kept in a sling, and an aperient mixture with ammonia given during the next day. By this time the swelling of the arm had subsided, and on the morning of the following day she was sufficiently well to resume her ordinary duties.

Three days afterwards, she was again stung-this time at the back of the neck. In a very few minutes she felt so depressed, weak, and faint, that she had to be supported upstairs to bed. In half an hour her face was of a dusky, red colour, and swollen, and her body covered with an eruption, and she suffered from violent headache. I gave her a glass of brandy and hot water, and soon she felt much better. I saw her again in four hours. She then complained of urgent thirst, and was very restless-felt inclined to, but could not, sleep. Her throat felt hot and painful ; and on examination, I found her tonsils red and swollen. Her pulse was quick and full. I ordered the neck to be bathed frequently and her throat to be gargled with hot water, and barley-water to be given to drink. I again saw her about five o'clock in the morning. Her throat-symptoms were somewhat relieved, but she was still very restless, and the eruption which remained was of a dusky hue, very like the rash of measles. There was well-marked coryza. In the course of the day she went home; and I heard from her frequently. The eruption lasted for three days and then began to fade; and now-six days from the date of the sting - she reports herself well, but weak.

On August 25th, my page and housemaid were both stung in the hand. The page had a swollen hand and arm, and much local pain for 
about twenty-four hours. He found relief from the application of vinegar. The housemaid did not suffer for more than ten minutes, and felt benefit from the application of damp washing-soda.

On August 26th, my nurse was stung on the right upper eyelid, and felt immediately much depression, local pain, and severe headache. A little brandy and warm water and the local application of laudanum soon gave relief, but the eyelid remained swollen for two days.

I also visited about this time three patients (females) suffering with swollen arms and hands from wasp-stings. The swelling remained in each case about a day. In one, relief was obtained from ammonia liniment ; in another, from vinegar ; and in the last, from the application of a damp blue-bag, such as is used by washerwomen.

I have either heard it stated, or have read that, the poisonous matter of the wasp-sting has an acid reaction. This I doubt. It may be slightly alkaline, but I think probably neutral. The latter would account for many opposite and different substances giving relief. Many things have been recommended as local applications; for instance, compound camphor liniment, soap liniment, eau-de-Cologne, brandy, whiskey-and, in fact, all the spirits in common use-chalk, vinegar, spirits of sal-volatile, carbonate of soda, spirits of hartshorn, ice, honey, sugar and soap, ipecacuanha, poultices, etc. In this neighbourhood, the old women pin their faith on washing-soda or damp blue-bags.

I would suggest that the treatment be as follows. A careful examination of the wound should be made with a good pocket-lens, and any rem. nant of the sting removed with a pair of fine-pointed forceps. Laudanum should be applied by means of a cotton-wool swab for at least ten minutes, followed by warm water fomentations. Internally, brandy and hot water should be given at once, and twenty minims of aromatic spirit of ammonia every half hour as long as there is depression. If the mouth or throat be stung, warm flannels should be applied to the neck, and warm inhalations with ether employed. There is sure to be spasm of the rima glottidis in these cases. In no case that $I$ have seen yet would I have given opium internally; I doubt anything but mischief from its use in any of these cases, but I am aware it has been reconımended by medical writers. If local pain be not subdued by the application of the laudanum, then I think I would try the effect of a hyoscyamus poultice or tincture of belladonna sprinkled over a warm damp flannel, and applied to the wound.

\section{CLINICAL MEMORANDA.}

\section{A CASE OF SPORADIC CHOLERA: EXTREME COL- LAPSE : RECOVERY UNDER ELIMINATIVE TREATMENT.}

I was sent for to a blacksmith of this town about $8 \mathrm{~A}$. M. on Augus 29th. He had gone to bed well, and awoke about 3 A.M. with diarrhcee and vomiting. He became rapidly worse; and, when I saw him, he was suffering horribly from cramp all over the body, especially the bands, arms, and bowels. The evacuations from the stomach and bowels were like water with a sediment of rice. The pulse was small and thready; his complexion, naturally fair, was now of a dusky hue ; his breathing was short, but not hurried; and he complained of constriction of his chest, "as if it were tied down." At Io A.M., he was altogether worse; his pulse was not perceptible at the wrist; the surface of the body was cold, especially the extremities; the cramps were very severe. The purging and vomiting continued. At II.30 A.M., the complexion was bluish; the surface quite clear. No pulse could be felt. Vomiting and purging occurred quite as often; the cramps were less severe. He was in a state of general apathy. Altogether the case seemed quite hopeless, and the patient moribund. At 4 P.M. slight reaction had set in. The general appearance was much the same, but the pulse could be felt. The cramps were only occasional and slight. Vomiting had ceased more than an hour. The bowels were still purged; the evacuations were the same as before. The improvement continued, and on the morning of the 3oth the skin had resumed its natural fairness. He had passed some urine, for the first time since the commencement of the attack, early this morning; and the bowels had acted twice in the night; the motions were of a delicate pale yellow, and they continued so for more than a week. There was no check in his progress to complete recovery.

I attended very many cases in Monmouthshire, during the epidemic of cholera in 1849 , with milder symptoms, which yet proved fatal under the treatment then pursued. I well recollect at the time thinking that we did more harm than good. I have been in the habit for many years of treating diarrhoea and English cholera with laxatives, such as rhubarb and magnesia with ginger and atomatic spirits of am- monia, with an occasional dose of grey powder, and always vith benefit; and, though I was thoroughly dissatisfied with the astrinfent method of treating cholera in 1849 , yet I doubt if I should have treated this case on the principle of eliminating a poison-in fact, assistng Nature to effect a cure-if I had not read Dr. George Johnson's papes upon the subject. The prostration is so great, and apparently ircreasing with the drain from the system by the purging and vomiting that we naturally strive to arrest the flux by astringents, and support the strength and restore the vital energy by stimulants. But his expla. nation of the cause of the collapse, by the impeded circulation through the lungs, quite convinced me. If the poison could cause such spasm of the minute arteries of the lungs, it would also cause the severe muscular cramps ; while the purging and vomiting are merely an effort of Nature to get rid of the poison. So I determined, if I ever had to treat cases of Asiatic cholera, to carry out the eliminating principle $\alpha$ treatment; and in this case the only medicine I gave was a mixture of rhubarb and magnesia, etc., every two hours. I also used a strong turpentine fomentation over the chest and bowels, frequently repeated, and continued until the reaction had been established. I used the tu:pentine fomentation in consequence of the great relief that follows its application in severe cases of cramp of the stomach, and so trusted to its assisting to relieve the constricted arterioles of the lungs. The patient said : "The fomentation has saved my life ; I felt as if a weight was lifted off my chest." Of course every care has been taken to prevent the disease from spreading.

I trust that the account of this case will interest the members of our profession, and induce those who may have the opportunity to try the eliminating plan of treatment. It will be seen that the discharges continued until reaction was completely established.

Kington, Hereford. Gustavus Foote, M.R.C.S., etc.

\section{EFFECTS OF BROMIDE OF POTASSIUM.}

IN reference to the question proposed by a correspondent in the last week's JOURNAL, regarding the possibly ill effects that may arise from the protracted use of the bromide of potassium, I furnish the subjoined account of a case that may shed some little light upon the subject.

On June 6th of this year, Mrs. H., aged 52, consulted me for epileptic attacks occurring once or twice a week, from which she had suf fered for many months. These I could not attach to any distinct local mischief, so, at once and solely, I prescribed half-drachm doses of the bromide of potassium, to be taken night and morning. The patient returned to me on the 26 th of the same month. She said she felt very well, had slept better since taking the medicine, and been free from any seizure. I told her to go on with the medicine for two or three weeks longer. She came to me again on July 25 th. There had been no more epilepsy, but she exhibited an unwontec aspect and deportment. She had a sad and sunken expression of countenance, an unsteadiness of gait, a general atony-a sort of ataxia - of the whole muscular system, as if a general shaking palsy were imminent. I could not resist the conclusion that before me were the toxic effects of the bromide, which she had been taking for more than six weeks. I told the patient that she would soon be relieved, and that I would change her medicine. In fact, I prescribed a simple stomachic, rather as a placebo than for any effect other than negative; telling her to take it for two or three weeks, and then to see me again. She returned to me on the 28 th August, stating that she began to improve very shortly after the last consultation, and that she was now (as she looked) quite well.

Manchester, September 16th, 187i. DANiEL NoBLE, M.D.

\section{EFFECTS OF BROMIDE OF POTASSIUM.}

IN reference to the note under the above heading, I beg to say that $I$ have used the bromide of potassium for some years past very largely in the treatment of insanity; and although, in occasional instances, temporary depression, loss of weight, and slight furunculoid eruptions have followed its use, yet its general effects have been most satisfactory, and untoward symptoms have manifested themselves with extreme rarity. In two cases, however - the one of mania, the other of acute melan cholia-scruple doses, given three times a day, produced within a week extreme depression, rapid wasting, impairment of muscular power, dilatation of pupils, hesitation of speech, and great taciturnity, together with loss of mental power, amounting almost to "paralysis of thought" - a condition presenting the strongest resemblance to that which accompanies brain-exhaustion by whatever causes produced. In both these cases, suspension of the bromide was rapidly followed by the disappearance of its ill effects. Dr. Bazire makes the following remarks with reference to this remedy:- "Diminished sensibility, followed by complete anæsthesia of the soft palate, uvula, and upper part of the 